\title{
Structural features, kinetics and SAR study of radical scavenging and antioxidant activities of phenolic and anilinic compounds
}

\author{
Hussein M Ali ${ }^{1,3 *}$, Ahmed Abo-Shady ${ }^{1}$, Hany A Sharaf Eldeen ${ }^{1}$, Hany A Soror ${ }^{1}$, Wafaa G Shousha², \\ Osama A Abdel-Barry ${ }^{1}$ and Ahmed M Saleh ${ }^{2}$
}

\begin{abstract}
Background: Phenolic compounds are widely distributed in plant kingdom and constitute one of the most important classes of natural and synthetic antioxidants. In the present study fifty one natural and synthetic structurally variant phenolic, enolic and anilinic compounds were examined as antioxidants and radical scavengers against DPPH, hydroxyl and peroxyl radicals. The structural diversity of the used phenolic compounds includes monophenols with substituents frequently present in natural phenols e.g. alkyl, alkoxy, ester and carboxyl groups, besides many other electron donating and withdrawing groups, in addition to polyphenols with 1-3 hydroxyl groups and aminophenols. Some common groups e.g. alkyl, carboxyl, amino and second $\mathrm{OH}$ groups were incorporated in ortho, meta and para positions.
\end{abstract}

Results: SAR study indicates that the most important structural feature of phenolic compounds required to possess good antiradical and antioxidant activities is the presence of a second hydroxyl or an amino group in o- or p-position because of their strong electron donating effect in these positions and the formation of a stable quinone-like products upon two hydrogen-atom transfer process; otherwise, the presence of a number of alkoxy (in 0 or $p$-position) and /or alkyl groups (in $o, m$ or $p$-position) should be present to stabilize the resulted phenoxyl radical and reach good activity. Anilines showed also similar structural feature requirements as phenols to achieve good activities, except o-diamines which gave low activity because of the high energy of the resulted 1,2-dimine product upon the $2 \mathrm{H}$-transfer process. Enols with ene-1,2-diol structure undergo the same process and give good activity. Good correlations were obtained between DPPH inhibition and inhibition of both $\mathrm{OH}$ and peroxyl radicals. In addition, good correlations were obtained between DPPH inhibition and antioxidant activities in sunflower oil and liver homogenate systems.

Conclusions: In conclusion, the structures of good anti radical and antioxidant phenols and anilines are defined. The obtained good correlations imply that measuring anti DPPH activity can be used as a simple predictive test for the anti hydroxyl and peroxyl radical, and antioxidant activities. Kinetic measurements showed that strong antioxidants with high activity have also high reaction rates indicating that factors stabilizing the phenoxyl radicals lower also the activation energy of the hydrogen transfer process.

Keywords: Antioxidant activity, Phenols, Anilines, DPPH, Hydroxyl radicals, Phenoxyl radicals, Structural features, SAR

\footnotetext{
* Correspondence: husseinaliali@yahoo.com

1 Department of Agricultural Biochemistry, Faculty of Agriculture, Ain Shams

University, Cairo, Egypt

${ }^{3}$ Present address: Faculty of Science For Girls, Chemistry Department,

Dammam University, Dammam, SA 31113, P.O. Box 838, Saudi Arabia

Full list of author information is available at the end of the article
} 


\section{Background}

Phenolic compounds are widely distributed in plant kingdom and constitute one of the most important classes of natural (e.g. $\alpha$-tocopherol, gallic acid and syringic acid) and synthetic (e.g. BHT, BHA and TBHQ) antioxidants [1-4]. Even simple phenolsshow wide variations in their chemical structures that include monophenols (e.g. cresols and eugenol), polyphenols (e.g. catechols and hydroquinones), substituted benzoic acid (e.g. salicylic and vanillic acids) and cinnamic acid (e.g. caffeic acid), and terpenoids (e.g. thymol and carvacrol). A few reports indicated that anilines also express radical scavenging and antioxidant activities [5-8]; where some of them present naturally in living cells (e.g. $o$ - and $p$-aminobenzoic acids). Phenolic antioxidants are generally believed to form phenoxyl radical upon donating a hydrogen atom that could quench active free radicals and stop the propagation of lipid peroxidation $[9,10]$. The number and position of aromatic hydroxyl groups were found to have strong impact on the activity of phenolic antioxidants [11-13]. The presence of $o$-hydroxyl group was reported to lower the $\mathrm{O}-\mathrm{H}$ bond dissociation energy and hence increase the hydrogen atom donation ability [13-16] and considered the most important structural feature of the high activity [11,17]. Electron donating groups, especially alkyl and methoxy groups were reported to increase the electron density of the phenoxyl radicals leading to enhancement of the radical scavenging and antioxidant activity [18]. The high activity of $\alpha$-tocopherol was attributed to the $p$-alkoxy group and the methyl groups on the aromatic ring [19].

Fifty one structurally variant phenolic and anilinic compounds were examined as radical scavengers against $\mathrm{DPPH}$, hydroxyl and peroxyl radicals, and as antioxidants in sunflower oil and liver homogenate systems. Kinetics $v s$ thermodynamics of scavenging hydroxyl radical was examined.

\section{Experimental}

\section{Chemicals}

All chemicals were obtained as reagent grade from Aldrich, Sigma or Fluka chemical companies and used without further purification.

\section{DPPH radical scavenging activity}

The 2, 2-diphenyl-1-picrylhydrazyl (DPPH) radical scavenging ability of the examined compounds was measured according to Brand-Williams, Cuvelier, \& Berset [20]. The examined compound $(25 \mu \mathrm{L}, 5 \mathrm{mM})$ or $25 \mu \mathrm{L}$ methanol (as a control) with $2.5 \mathrm{ml} 0.004 \% \mathrm{DPPH}$ in methanol $(0.1 \mathrm{mM})$, were mixed. The solution was incubated for 20 $\mathrm{min}$ at room temperature before reading the absorbance (A) at $517 \mathrm{~nm}$ against methanol as blank. The inhibitory percentage of DPPH was calculated according to the following equation:

$$
\begin{array}{r}
\text { \% DPPH radical ascavinging activity } \\
=100-\left(\frac{A 517(\text { Exp })}{A 517(\text { control })} \times 100\right)
\end{array}
$$

\section{\% Hydroxyl radical scavenging activity}

Hydroxyl radical scavenging activity of the examined compounds was measured based on the method of Halliwell, Gutteridge, \& Arouma [21], with a slight modification according to Jiang, Bank, \& Scholes [22]. Briefly, $200 \mu \mathrm{L}$ deoxyribose solution $(2.8 \mathrm{mM}), 200 \mu \mathrm{L}$ $\mathrm{H}_{2} \mathrm{O}_{2}(1.4 \mathrm{mM})$ and $200 \mu \mathrm{L}$ of the examined compound $(5 \mathrm{mM})$ or oxygen free water (control), were placed in a test tube. Fenton reaction was initiated by the addition of $200 \mu \mathrm{L}$ EDTA $(100 \mu \mathrm{M}), 200 \mu \mathrm{L} \mathrm{FeCl}_{2}$ solution $(20 \mu \mathrm{M}$ in $1 \mathrm{mM} \mathrm{HCl}$ ); all used solutions were oxygen free. The total volume of the reaction mixture $(1 \mathrm{ml})$ was mixed and incubated for 10 second at room temperature. The reaction was stopped by the addition of $1 \mathrm{ml} 10 \%$ trichloroacetic acid (TCA), then $1 \mathrm{ml} \mathrm{1 \%}$ thiobarbituric acid (TBA) solution in $50 \mathrm{mMNaOH}$ containing $0.02 \%$ butylatedhydroxyanisole (BHA) was added. The mixture was heated at $80^{\circ} \mathrm{C}$ for 15 minutes then cooled and the absorbance (A) was measured at $532 \mathrm{~nm}$. The hydroxyl radical scavenging activity was calculated according to the following equation:

$$
\begin{aligned}
& \% \text { OH radical scavinging activity } \\
& \quad=100-\left(\frac{A 532(\text { Exp })}{\text { A532(control })} \times 100\right)
\end{aligned}
$$

\section{Rate constant of scavenging hydroxyl radical}

The rate constant (ks) of hydroxyl radical scavenging reaction was measured by using the previous method of the deoxyribose model [21]. The same procedure was adopted by using various concentrations of the examined compounds ( $0-1 \mathrm{mM}$ final concentration), and then the following equation was applied using a linear regression analysis by plotting $1 / \mathrm{A} v s[\mathrm{~S}]$.

Where: A is the absorbance in the presence of the examined compound, Aoisthe absorbance in the absence of the examined compound, $\mathrm{k}_{\mathrm{DR}}$ is the second order rate constant of the reaction of deoxyribose with hydroxyl radical $\left(3.1 \times 10^{6} \mathrm{M}^{-1} \mathrm{Sec}^{-1}\right)$, [S] is the molar concentration of the scavenger, [DR] is the molar concentration of deoxyribose $(0.56 \mathrm{mM})$, and $\mathrm{ks}$ is the second order rate constant $\left(\mathrm{mM}^{-1} \mathrm{Sec}^{-1}\right)$ of the reaction of a compound with the hydroxyl radical.

\section{Peroxyl radical scavenging activity}

Scavenge peroxyl free radicals was estimated by ORAC method described by Cao \& Prior [23] and modified by 
Gerhäuser et al [24]. AAPH, 2,2-azobis (2-amidinopropane) dihydrochloride, was used as peroxyl radical generator while $\beta$-phycoerythrin $(\beta$-PE) was used as a redox-sensitive fluorescent indicator protein. Fluorescence was measured at $37^{\circ} \mathrm{C}$ for $100 \mathrm{~min}$ until completion using Microplate reader FluoStarOptimum with excitation at $540 \mathrm{~nm}$ and emission at $565 \mathrm{~nm}$. Trolox was used as standard where one ORAC unit is equal to the net protection of $\beta$-PE produced by $1 \mu \mathrm{M}$ trolox.

\section{Antioxidant activity in sunflower oil}

An antioxidant activity assay was carried out in sunflower oil as described by Osawa \& Namiki [25], with slight modification. The examined compound $(0.2 \mathrm{ml}, 5 \mathrm{mM}$ in Methanol) or $0.2 \mathrm{ml}$ methanol (control) was added to a solution of sunflower oil ( $0.2 \mathrm{ml}$ oil, $10 \mathrm{ml} 99.8 \%$ ethanol and $10 \mathrm{ml} 0.2 \mathrm{M}$ phosphate buffer $\mathrm{pH} \mathrm{7.0)}$. The total volume was adjusted to $25 \mathrm{ml}$ with distilled water. The reaction mixture was incubated at $30^{\circ} \mathrm{C}$ for $24 \mathrm{hrs}$, then the degree of oxidation was measured according to the thiocyanate method by sequentially adding ethanol $(10 \mathrm{ml}$, $75 \%)$, ammonium thiocyanate $(0.2 \mathrm{ml}, 30 \%)$, sample solution $(0.2 \mathrm{ml})$, and ferrous chloride $(0.2 \mathrm{ml}, 20 \mathrm{mM}$ in $3.5 \% \mathrm{HCl})$. After the mixture was stirred for 3 minutes, the peroxide value was determined by reading the absorbance (A) at $500 \mathrm{~nm}$. The percentage inhibition of oil acid peroxidation was calculated according to the following formula:

$$
\% \text { Antioxidant activity }=100-\left(\frac{A 500(\text { Exp })}{A 500(\text { control })} \times 100\right)
$$

\section{Antioxidant activity in rat liver}

Albino rabbit liver was used. Liver tissue $(4 \mathrm{~g})$ was sliced and homogenized in $22.5 \mathrm{ml} \mathrm{KCl-Tris} \mathrm{HCL}$ buffer (150 $\mathrm{mM}, \mathrm{pH} 7.2$ ) and centrifuged at $5000 \times \mathrm{g}$ for 10 minutes to give supernatant of liver homogenate. The effect of anti- $\mathrm{FeCl}_{2}$-ascorbic acid stimulated lipid peroxidation was determined by the method of Yoden, Lio, \& Tabata [26]. The liver homogenate $(0.4 \mathrm{ml}), 0.1 \mathrm{ml}$ Tris- $\mathrm{HCl}$ buffer $(\mathrm{pH} 7.2)$ and $0.2 \mathrm{ml}$ tested compound (5 $\mathrm{mM}$ in methanol) or $0.2 \mathrm{ml}$ methanol (control) were mixed and incubated for $1 \mathrm{~h}$ at $37^{\circ} \mathrm{C}$. After incubation, $0.5 \mathrm{ml} 0.1 \mathrm{~N}$ $\mathrm{HCl}, 0.5 \mathrm{ml}$ 0.9\% sodium dodecyl sulfate (SDS), and $0.5 \mathrm{ml}$ $\mathrm{H}_{2} \mathrm{O}$ were added and shaken with the incubation solution. TBA ( $2 \mathrm{ml}, 0.5 \%$ ) was added then the mixture was heated for 30 minutes in a boiling water bath. After cooling, $5 \mathrm{ml}$ $n$-butanol was added; the mixture was then shaken vigorously. The $n$-butanol layer was separated by centrifugation at $1000 \times \mathrm{g}$. The absorbance $(\mathrm{A})$ of the sample was read at $532 \mathrm{~nm}$ against a blank, which contained all reagents except antioxidant.

\section{Theoretical calculations and statistical analysis}

Heat of formation was calculated by MOPAC calculations using PM3 method in CambridgeSoft package (2000) after energy minimization. The electrophilic Brown parameter $\left(\sigma_{\mathrm{p}}^{+}\right)$of para substituents and Hammett parameter $(\sigma \mathrm{m})$ of meta substituents were obtained from the literature [27], while $\sigma_{\mathrm{o}}^{+}$for ortho substituents was calculated from the formula $\sigma_{\mathrm{o}}^{+}=0.66 \sigma_{\mathrm{p}}^{+}[28]$.

Regression analyses were performed using SPSS software version 16. Correlations were assessed by the correlation coefficient $\left(R^{2}\right)$, standard error of the estimate $(\mathrm{SE})$, the number of data point $(\mathrm{N})$, the least significant difference $(p)$, and the 95\%-confidence intervals (in parentheses) for each regression coefficient.

\section{Results and discussion}

Antioxidant and radical scavenging activities against $\mathrm{DPPH}$, hydroxyl and peroxyl radicals of a wide range of natural (e.g. $\alpha$-tocopherol, eugenol, thymol, carvacrol, caffeic acid, vanillic acid syringic acid and gallic acid) and synthetic phenolic compounds were examined; the results are presented in Table 1 . The structural diversity of the used phenolic compounds (Figure 1) includes monophenols with substituents frequently present in natural phenols e.g. alkyl, alkoxy, ester and carboxyl groups, besides many other electron donating and withdrawing groups; in addition to polyphenols with 1-3 hydroxyl groups and aminophenols. Some common groups e.g. alkyl, carboxyl, amino and second $\mathrm{OH}$ groups were incorporated in ortho, meta and para positions. Substituted anilines and enols (e.g. ascorbic and 4-hydroxycoumarin) as structurally and chemically related to phenols were also included.

\section{Structure-activity relationships (SAR)}

$\mathrm{DPPH}$ has frequently been used as a reactive hydrogen acceptor for the determination of radical scavenging activity of various natural and synthetic compounds [29]. Results listed in Table 1 indicate that the examined compounds (51 compounds) expressed anti DPPH radical activity ranged from 0 to $99.1 \%, 15$ of them (entries 2, 4, 5, 7, 22-24, 29-31, 34-37, 43) exhibited high scavenging activity ( $>$ 89.6). The fifteen highly active compounds possessed some special structural features that can be depicted in the following structure-activity relationships: (1) all polyphenols (7 compounds) with a second hydroxyl group in the ortho or para positions e.g. catechol and hydroquinone showed high activity (98 and $97 \%$ respectively); however, the meta isomer (resorcinol) showed very low activity (2.5\%). This result can be explained by the strong electron donation ability of the hydroxyl group in ortho and para positions $\left(\sigma_{\mathrm{p}}^{+}=-0.92\right.$, $\sigma_{\mathrm{o}}^{+}=-0.61$ ) while the hydroxyl in meta position is e.w.g. $(\sigma \mathrm{m}=0.12)$. It is well established that electron donating 
Table 1 Radical scavenging and antioxidant activities of phenols, enols and anilines

\begin{tabular}{|c|c|c|c|c|c|c|c|}
\hline Entry & Compound & \% DPPH inh. & Peroxyl inh. & $\% \mathrm{OH}$ inh. & $k^{a}$ & $\% A^{b}$ activity & $\% A^{c}$ activity \\
\hline 1 & Phenol & 2.3 & 0.0 & 0.4 & 0.83 & 0.0 & 0.0 \\
\hline 2 & Catechol & 98.0 & 1.8 & 70.0 & 402.59 & 54.0 & 49.0 \\
\hline 3 & Resorcinol & 2.5 & 0.8 & 5.1 & 9.40 & 4.0 & 5.0 \\
\hline 4 & Hydroquinone & 97.0 & 2.1 & 67.0 & 360.50 & 54.0 & 47.0 \\
\hline 5 & 2- Aminophenol & 92.0 & 1.49 & 63.1 & 307.42 & 46.0 & 40.0 \\
\hline 6 & 3-Aminophenol & 20.2 & 0.7 & 7.3 & 13.82 & 7.0 & 2.0 \\
\hline 7 & 4- Aminophenol & 97.0 & 1.4 & 65.0 & 333.41 & 44.0 & 40.0 \\
\hline 8 & 3- Nitrophenol & 1.3 & 0.89 & 2.9 & 5.36 & 5.0 & 4.0 \\
\hline 9 & 4- Nitrophenol & 1.1 & 0.0 & 5.6 & 10.51 & 5.0 & 6.0 \\
\hline 10 & 3-Chlorophenol & 3.1 & 1.1 & & & & \\
\hline 11 & 4- Chlorophenol & 3.6 & 0.81 & 1.7 & 3.04 & 0.0 & 0.0 \\
\hline 12 & 4-Hydroxybenzaldehyde & 1.1 & 0.3 & 4.6 & 8.29 & 2.0 & 3.0 \\
\hline 13 & 2-Hydroxyacetophenone & 0.0 & & & & & \\
\hline 14 & Phenol-4-sulfonic acid & 0.3 & 0.9 & 3.4 & 6.08 & 1.0 & 1.0 \\
\hline 15 & Salicylic acid & 1.3 & 0.9 & 8.9 & 17.14 & 1.0 & 2.0 \\
\hline 16 & 3-Hydroxybenzoic acid & 2.5 & 0.0 & 6.9 & 12.72 & 4.0 & 3.0 \\
\hline 17 & 4-Hydroxybenzoic acid & 1.8 & 0.56 & 2.5 & 4.48 & 3.0 & 1.0 \\
\hline 18 & Ethyl salicylate & 1.2 & 0.81 & & & & \\
\hline 19 & Methyl salicylate & 1.6 & 0.77 & & & & \\
\hline 20 & Ethyl 4-hydroxybenzoate & 1.9 & 0.47 & & & & \\
\hline 21 & 3,5-Dinitrosalicylic acid & 0.8 & 0.0 & 4.3 & 7.19 & 0.0 & 1.0 \\
\hline 22 & 3,4-Dihydroxybenzoic & 89.6 & 2.41 & 35.4 & 93.44 & 57.0 & 51.0 \\
\hline 23 & 2,5-Dihydroxybenzoic & 95.0 & 2.62 & 49.0 & 88.47 & 63.0 & 60.0 \\
\hline 24 & Ethyl 2,5-dihydroxybenzoate & 96.1 & 2.5 & & & & \\
\hline 25 & o-cresol & 12.2 & 0.62 & & & & \\
\hline 26 & p-Cresol & 15.5 & 0.52 & & & & \\
\hline 27 & Thymol & 35.0 & & & & & \\
\hline 28 & Carvacrol & 33.9 & & & & & \\
\hline 29 & Butylatedhydroxytoluene (BHT) & 96.0 & 2.98 & 95.0 & 361.61 & 66.0 & 59.0 \\
\hline 30 & a-Tocopherol & 96.2 & & 68.8 & 373.77 & 47.0 & 45.0 \\
\hline 31 & Eugenol & 98.1 & & 97.0 & 389.81 & 63.0 & 60.0 \\
\hline 32 & Guaiacol(o-methoxyphenol) & 28.3 & & & & & \\
\hline 33 & Vanillic acid & 25.1 & 0.8 & 2.7 & 5.03 & 2.1 & 2.3 \\
\hline 34 & Syringic acid & 90.4 & 2.9 & 62.2 & 283.09 & 58.0 & 52.0 \\
\hline 35 & Gallic acid & 92.0 & 3.09 & 65.0 & 331.20 & 61.0 & 59.0 \\
\hline 36 & Caffeic acid & 91.2 & 2.78 & 53.5 & 196.29 & 62.0 & 57.0 \\
\hline 37 & Ascorbic acid & 99.1 & 2.94 & 81.0 & 361.61 & 46.0 & 49.0 \\
\hline 38 & 4- hydroxycoumarin & 1.5 & & 2.4 & 3.59 & 0.0 & 0.0 \\
\hline 39 & 1-Naphthol & 35.0 & 1.23 & & & & \\
\hline 40 & Aniline & 8.7 & & 8.6 & 16.59 & 2.0 & 6.0 \\
\hline 41 & p-Tuluidine & 18.4 & & & & & \\
\hline 42 & p-Anisidine & 31.1 & & 4.9 & 8.85 & 6.0 & 3.0 \\
\hline 43 & p-Phenylenediamine & 90.1 & & 66.0 & 347.78 & 43.0 & 49.0 \\
\hline
\end{tabular}


Table 1 Radical scavenging and antioxidant activities of phenols, enols and anilines (Continued)

\begin{tabular}{lllllll}
\hline 44 & o-Phenylenediamine & 5.1 & 2.8 & 5.032 & 3.0 & 1.0 \\
45 & 2,3-Diaminophethaline & 2.9 & 5.5 & 9.95 & 5.0 & 4.0 \\
46 & Anthranillic acid & 5.7 & & & \\
47 & p-Aminobenzoic acid & 4.6 & & \\
48 & m-Bromoaniline & 0.0 & & \\
49 & p-Chloroaniline & 0.0 & & \\
50 & o-Nitroaniline & 0.0 & & & \\
51 & p-Nitroaniline & 0.0 & & & \\
\hline
\end{tabular}

${ }^{\mathrm{a}}$ Bimolecular rate constant, $\mathrm{ks} \times 10^{-7}\left(\mathrm{M}^{-1} \mathrm{~s}^{-1}\right)$.

b $\%$ Antioxidant activity in sunflower system.

c \% Antioxidant activity in liver homogenate system.

groups stabilize the resulted phenoxyl radicals through inductive (as in alkyl substituents) or resonance (as in OMe or $\mathrm{NH}_{2}$ substituents) effect; thus lower the $\mathrm{O}-\mathrm{H}$ bond energy and enhance the radical scavenging activity. In contrary, electron withdrawing groups stabilize more the phenols and destabilize the resulted radicals [30-32]. In addition, a hydrogen bonding can be formed between the phenoxyl unpaired electron and the adjacent hydroxyl group in catechols that stabilizes the radicals formed more than it does for the parent diols<smiles>C=CCc1ccc(O)c(OC)c1</smiles> 


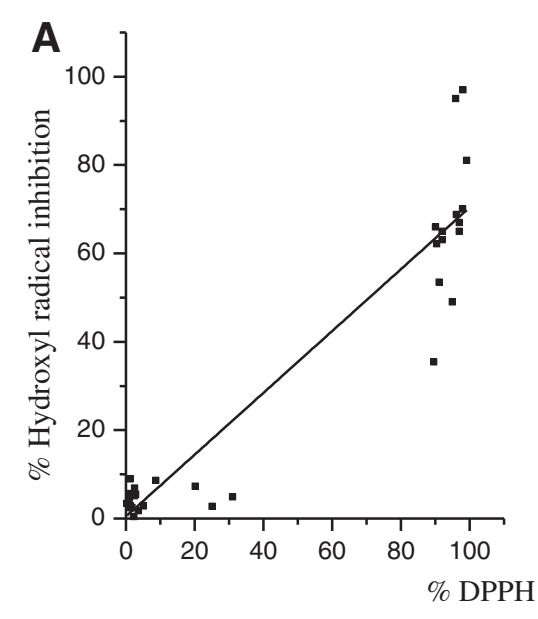

Figure 2 Correlations between \% DPPH inhibition and each of \% of hydroxyl (A) and peroxyl (B) radical inhibition.
[33-35]. It is also known that catechol and hydroquinone undergo two hydrogen-atom transfer process to give the stable $o$ - and $p$-quinones respectively [10]. Ascorbic acid is well known good antioxidant [36] and exhibited high activity reached $99.1 \%$. It could also undergo the two hydrogen-atom transfer process to give the dehyroascorbic acid [37]. (2) Similarly, $o$ - and $p$-aminophenols showed high activity (92 and $97 \%$ respectively) because of the strong electron donating effect of the amino group in these positions $\left(\sigma_{\mathrm{p}}^{+}=-1.30, \sigma_{\mathrm{o}}^{+}=-0.86\right)$ and the possible formation of 2- and 4-iminoketones respectively. However, $m$-aminophenol gave moderate activity $(20.2 \%)$ compared to resorcinol (2.5\%), since the amino group is still e.d.g. in the $m$-position $(\sigma \mathrm{m}=-0.16)$ while the hydroxyl group is e.w.g. $(\sigma \mathrm{m}=0.12)$ in the same position. (3) Most other monophenols with various substituents e.g. carboxyl (entries 15-17), ester (entries 18-20), $\mathrm{CHO}$ (entry 12), $\mathrm{CH}_{3} \mathrm{CO}$ (entry 13 ), $\mathrm{SO}_{3} \mathrm{H}$ (entry 14 ), $\mathrm{NO}_{2}$ (entries 8-9) and $\mathrm{Cl}$ (entries 10-11) gave low activity $(<3.6 \%)$. However, the presence of one alkyl group as in $o$ - and $p$-cresol raised the activity to 12.2 and $15.5 \%$ respectively compared to that of phenol (2.3\%), while two alkyl groups as in thymol and carvacrol (in $o$ - and $m$-positions) increased the activity to 35.0 and $33.9 \%$ respectively; these results indicate that alkyl groups in any position $(o, m$ or $p)$ stabilize the phenoxyl radicals through inductive effect and thus enhance the antradical activity. The activity of thymol and carvacrol was previously reported [38]. Although three alkyl groups in BHT gave high activity (96.0\%), this activity is exceptionally high where BHT showed special antiradical mechanism [39]. The presence of methoxy group alone (guaiacol) or with carboxyl group (vanillic acid) gave moderate activity (28.3 and $25.1 \%$ respectively) while two methoxy groups in syringic acid gave high activity (90.4\%). This result confirmed the impact of alkyl and alkoxy groups as good e.d.g. in increasing the electron density and stabilizing of the phenoxyl radicals. However, it should be noted that methoxy group, in contrary to alkyl groups, has to be in $o$ - or $p$-position to act as good e.d.g. as indicated by Brown parameter $\left(\sigma_{\mathrm{p}}^{+}=-0.78, \sigma_{\mathrm{o}}^{+}=-0.51\right)$. On the other hand, the $m$-methoxy group works normally as e.w.g. as indicated by sigma parameter $(\sigma \mathrm{m}=0.12)$ but the strong electron withdrawing activity of an oxygen phenoxyl radical causes the $m$-methoxy group to become weak e.d.g., $\sigma_{\mathrm{m}}^{+}=-0.14$ [40]. These results suggest that both alkyl and alkoxy groups, in the proper positions, seem to enhance the activity in additive way which could be applied and examined in a QSAR study (Ali \& Ali, personal

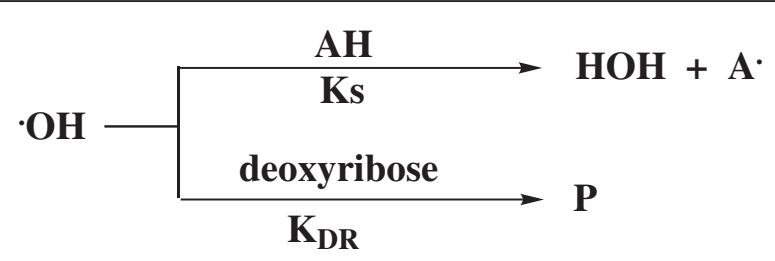

Scheme 1 Possible reactions of hydroxyl radical in the reaction mixture. Reaction rate $=k_{s}[O H][A H]+k_{D R}[O H][D R]$. 


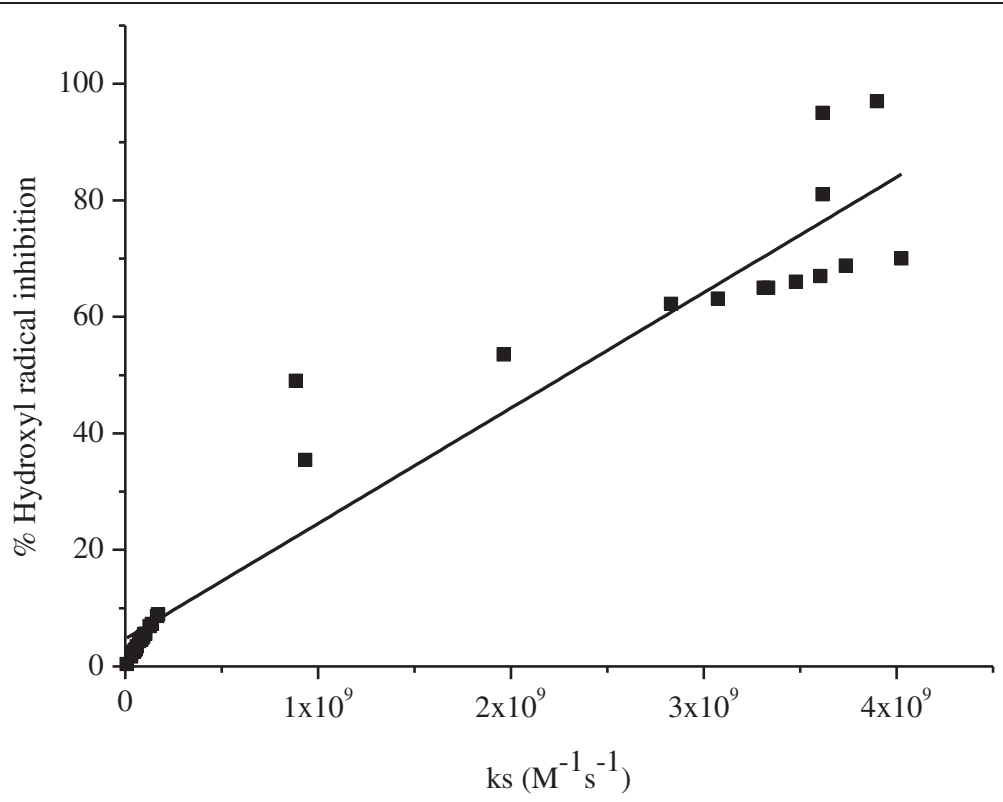

Figure 3 Correlation between $\% \mathrm{OH}$ radical inhibition and the rate constant $(\mathrm{ks})$.

communications). (4) Anilines gave the same trends as phenols; some of the preliminary aniline antioxidant activity results were previously reported [41]. $p$ Phenylenediamine, as might be expected, gave high activity $(90.1 \%)$ as a result of electron donating effect of the amino group and the possible two hydrogen-atom transfer process leading to the formation of 1,4-diimine; however, $o$-phenylenediamine gave low activity $(5.1 \%)$ which could be attributed to the strain energy manifested by the relatively high heat of formation of the 1,2-diimine $\left(\Delta \mathrm{H}_{\mathrm{F}}=\right.$ $119.47 \mathrm{Kcal} / \mathrm{mole}$ ) formed from the $o$-isomer compared to that of 1,4-diimine $\left(\Delta \mathrm{H}_{\mathrm{F}}=73.41 \mathrm{Kcal} / \mathrm{mole}\right)$ resulted from the $p$-isomer as deduced by MOPAC calculations. This result is confirmed by the low activity expressed by the 2,3-diaminonaphthaline (2.9\%). As in substituted phenols, aniline has low activity (8.7\%) while the $p$-methyl group in $p$-toluidine raised the activity to $18.4 \%$ and $p$-methoxy in $p$-anisidine has even higher effect (31.1\%); other substituents (carboxyl, bromo, chloro or nitro substituents) showed little negative effect.

\section{Scavenging hydroxyl and peroxyl radicals}

To examine the validity of using the simple DPPH test as indicator for the activity towards other radicals, scavenging the $\mathrm{OH}$ radical, one of the most reactive radicals presents in living cells [42,43], and peroxyl radical,

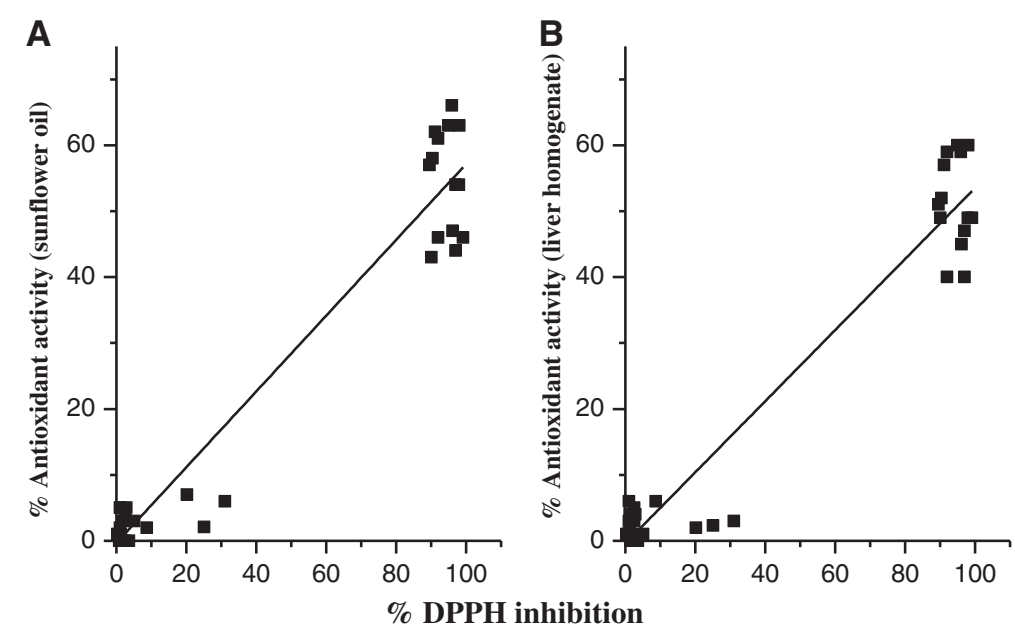

Figure 4 Correlations between \% DPPH inhibition and the antioxidant activity against lipid peroxidation in each of sunflower oil (A) and liver homogenate (B). 
usually formed naturally upon lipid peroxidation [15], were determined; the results are listed in Table 1. The trends of scavenging both hydroxyl and peroxyl radicals are much similar to that of DPPH radical as presented by eqs. 1 and 2 respectively and plotted in Figure 2 .

$$
\begin{gathered}
\begin{aligned}
\text { OH inhibition }=0.46( \pm 2.77) \\
+0.70( \pm 0.04) \% \mathrm{DPPH} \text { inhibition }
\end{aligned} \\
\begin{aligned}
\mathrm{N}=32, \mathrm{R}^{2}=0.894, \mathrm{SE}=11.01, \mathrm{p}<0.001
\end{aligned}
\end{gathered}
$$

$$
\begin{gathered}
\text { Peroxyl radical inhibition }=0.48( \pm 0.11) \\
+0.02( \pm 0.00) \% \mathrm{DPPH} \text { inhibition } \\
\mathrm{N}=32, \mathrm{R}^{2}=0.793, \mathrm{SE}=0.46, \mathrm{p}<0.001
\end{gathered}
$$

\section{Thermodynamic vs kinetic of $\mathrm{OH}$ radical scavenging activity}

Although the \% hydroxyl radical scavenging activity determines the ability of antioxidant to scavenge the hydroxyl radicals, it does not give direct measure of the intrinsic reactivity of these antioxidants. Good antioxidants should have high scavenging activity (thermodynamic property) and relatively high reaction rate (kinetic property); therefore, the second order rate constant (ks) of the $\mathrm{H}$-atom transfer from antioxidant to the hydroxyl radical was determined in the deoxyribose assay. In this assay the hydroxyl radicals may react with either the antioxidant $(\mathrm{AH})$ or the deoxyribose (DR) in parallel fashion mechanism (Scheme 1).

The rate constants (ks) listed in Table 1 show, as expected, a high reactivity of the hydroxyl radical towards most compounds even those with low scavenging activity, expressed by high rate constant that ranged from $8.29 \times 10^{6}$ (phenol) $-4.03 \times 10^{9}$ (catechol) $\mathrm{M}^{-1} \mathrm{~s}^{-1}$. In addition, compounds with the highest $\mathrm{DPPH}$ and $\mathrm{OH}$ radical scavenging activities showed also the highest rate constant $\left(8.85 \times 10^{8}-4.03 \times 10^{9} \mathrm{M}^{-1} \mathrm{~s}^{-1}\right)$. The strong correlation between $\%$ of $\mathrm{OH}$ radical inhibition and rate constant is presented by eq. 3 and Figure 3.

$$
\begin{aligned}
& \begin{aligned}
\% \mathrm{OH} \text { radical inhibition }= & 4.72( \pm 1.98) \\
& +1.98 \times 10^{-8}( \pm 0.00) \mathrm{ks}
\end{aligned} \\
& \mathrm{N}=32, \mathrm{R}^{2}=0.937, \mathrm{SE}=8.52, \mathrm{p}<0.001
\end{aligned}
$$

\section{Antioxidant activity}

Antioxidant activity against lipid peroxidation in two systems, sunflower oil and liver homogenate, was determined (Table 1). The strong radical scavengers showed also good antioxidant activity which implies similar structural requirements and the dependence of antioxidant activities on radical scavenging activities. The strong correlations between antioxidant activities in both systems and DPPH inhibition is presented by eqs. 4 and 5 respectively, and Figure 4.

$$
\begin{aligned}
& \% \text { antioxidant activity ( sunflower oil })=-0.34( \pm 1.66) \\
& +0.58( \pm 0.03) \% \mathrm{DPPH} \text { inhibition } \\
& \mathrm{N}=32, \mathrm{R}^{2}=0.941, \mathrm{SE}=6.61, \mathrm{p}<0.001
\end{aligned}
$$

$\%$ antioxidant activity (liver homogenate $)=-0.39( \pm 1.57)$ $+0.54( \pm 0.03) \% \mathrm{DPPH}$ inhibition

$\mathrm{N}=32, \mathrm{R}^{2}=0.940, \mathrm{SE}=6.25, \mathrm{p}<0.001$

Therefore, presence of good e.d.g. with the ability to form stable quinone-like product or the presence of at least three alkyl or two alkoxy groups is still required for phenols or anilines to possess good antioxidant activity in oils or living cells.

\section{Conclusions}

These results imply that the structural features and factors required for good anti DPPH activity are also required for both anti $\mathrm{OH}$ and peroxyl radical activities and antioxidant activities in various systems. The factors are either the presence of $o$ - or $p$-hydroxyl or amino groups that could form quinone-like product, or the presence of a number of alkoxy (in $o$ or $p$-position) and/or alkyl groups (in $o, m$ or $p$-position) to stabilize the resulted phenoxyl radical. Kinetic measurements showed that strong antioxidants with high activity have also high reaction rates indicating that factors stabilizing the phenoxyl radicals lower also the activation energy.

\section{Competing interests}

The authors declare that they have no competing interests.

\section{Authors' contributions}

HMA designed the experiments, performed the SAR analysis and wrote the paper. AAS and WGS specified the research point and aims. HASE and HAS contributed to the experimental design and techniques, OAAB and AMS ran the experiments. All authors read and approved the final manuscript.

\section{Author details}

${ }^{1}$ Department of Agricultural Biochemistry, Faculty of Agriculture, Ain Shams University, Cairo, Egypt. ${ }^{2}$ Faculty of Science, Helwan University, Cairo, Egypt. ${ }^{3}$ Present address: Faculty of Science For Girls, Chemistry Department, Dammam University, Dammam, SA 31113, P.O. Box 838, Saudi Arabia.

Received: 20 October 2012 Accepted: 21 February 2013 Published: 16 March 2013

\section{References}

1. Balasundram N, Sundram K, Samman S: Phenolic compounds in plants and agro industrial by-products: Antioxidant activity, occurrence, and potential uses. Food Chem 2006, 99:191-203.

2. Khan HRA, Khan MR, Sahreen S, Ahmed M: Evaluation of phenolic contents and antioxidant activity of various solvent extracts of Sonchusasper L. Chemistry Central Journal 2012, 6:12-18.

3. Božin B, Mimica-Dukić N, Samojlik I, Anačkov G, Igić R: Phenolics as antioxidants in garlic (Allium sativum L., Alliaceae). Food Chem 2008, 111:925-929. 
4. Orèiæ DZ, Mimica-Dukiæ NM, Franciškoviæ MM, Petroviæ SS, Jovin EĐ: Antioxidant activity relationship of phenolic compounds in Hypericumperforatum L. Chemistry Central Journal 2011, 5:34-41.

5. Gizdavic-Nikolaidis M, Travas-Sejdic J, Kilmartin PA, Bowmaker GA, Cooney RP: Evaluation of antioxidant activity of aniline and polyaniline. Curr Appl Phys 2004, 4:343-346.

6. Ismail MN, Ibrahim MS, Abd El-Ghaffar MA: Polyaniline as an antioxidant and antirad in SBR vulcanizates. Polym Degrad Stab 1998, 62:337-341.

7. Ali HM, El-Qurashi MAM: Synthesis and application of some dianilinosilanes, bis (trimethylsilyl) phenylenediamines and dialkylbenzo1,3,2-diazasilolines as antioxidants. Phosphorus, Sulfur and Silicon 1998, 134/135:521-529.

8. El-Qurashi MAM, Ali HM: Anilinosilanes as thermo-oxidation stabilizers of commercial lubricating base oils. Thermochimica Acta 1997, 293:185-190

9. Cheng Z, Ren J, Li Y, Chang W, Chen Z: Establishment of a quantitative structure-activity relationship model for evaluating and predicting the protective potentials of phenolic antioxidants on lipid peroxidation. J Pharmaceutical Sci 2003, 92:475-484.

10. Foti M, Ruberto $\mathrm{G}$ : Kinetic solvent effects on phenolic antioxidants determined by spectroscopic measurements. J Agric Food Chem 2001, 49:342-348.

11. Cai Y-Z, Sun $M$, Xing J, Luo Q, Corke H: Structure-radical scavenging activity relationships of phenolic compounds from traditional Chinese medicinal plants. Life Science 2006, 78:2872-2888.

12. Lien EJ, Ren S, Bui H-H, Wang R: Quantitative structure-activity relationship analysis of phenolic antioxidants. Free Radic Biol Med 1998 26:285-294.

13. Tyrakowska B, Soffers AEMF, Szymusiak H, Boeren S, Boersma MG, Lemanska K, Vervoort J, Rietjens IMCM: TEAC antioxidant activity of 4hydroxybenzoates. Free Radic Biol Med 1999, 27:1427-1436.

14. De Pinedo AT, Peňalver P, Morales JC: Synthesis and evaluation of new phenolic-based antioxidants: structure-activity relationship. Food Chem 2007, 103:55-61.

15. Amorati R, Pedulli GF, Cabrini L, Zambonin L, Landi L: Solvent and $p H$ effects on the antioxidant activity of caffeic and other phenolic acids. J Agric Food Chem 2006, 54:2932-2937.

16. Lucarini M, Pedulli GF: Bond dissociation enthalpy of a-tocopherol and other phenolic antioxidants. J Org Chem 1994, 59:5063-5070.

17. Ordoudi SA, Tsimidou MZ, Vafiadis AP, Bakalbassis EG: Structure-DPPH scavenging activity relationships; parallel study of catechol and guaiacol acid derivatives. J Agric Food Chem 2006, 54:5763-5768.

18. Kajiyama T, Ohkatsu Y: Effect of para-substituts of phenolic antioxidants. Polym Degrad Stab 2001, 71:445-452.

19. Breese KD, Lamè the J-F, DeAmitt C: Improving synthetic hindered phenol antioxidants: learning from vitamin E. Polym Degrad Stab 2000, 70:89-96.

20. Brand-Williams W, Cuvelier ME, Berset C: Use of a free radical method to evaluate antioxidant activity. Food Sci Technol 1995, 28:25-30.

21. Halliwell B, Gutteridge JMC, Arouma Ol: The deoxyribose method: a simple "test-tube" assay for determination of rate constants for reactions of hydroxyl radicals. Anal Biochem 1987, 165:215-219.

22. Jiang J, Bank JF, Scholes CP: Structure and function of lipid soluble vitamins. J Am Chem Soc 1993, 115:4742-4746.

23. Cao G, Prior RL: The measurement of oxygen radical absorbance capacity in biological samples. Meth Enzymol 1999, 299:50-62.

24. Gerhäuser C, Klimo K, Heiss E, Neumann I, Gamal-Eldeen A, Knauft J, Liu GY, Sitthimonchai S, Frank N: Mechanism-based in vitro screening of potential cancer chemopreventive agents. Mutat Res 2003, 523-524:163-172.

25. Osawa T, Namiki M: A Novel type of antioxidant isolated from leaf wax of Eucalyptus leaves. J Agric Food Chem 1981, 45:735-739.

26. Yoden K, Lio T, Tabata T: Measurment of thiobarbituric acid value in tissue homogenate solutized with sodium dodecyl sulphate. Yakugaku Zasshi 1980, 100:553-559.

27. Hansch C, Leo A: Exploring QSAR Fundamental And Applications in Chemistry And Biology. Washington, DC: American Chemical Society; 1995.

28. Jonsson M, Lind J, Eriksen TE, Merenyi G: O-H bond strengths and oneelectron reduction potentials of multisubstituted phenols and phenoxy radicals. Predictions using free energy relationships. J Chem Soc, Perkin Trans I| 1993:1567-1568.

29. Molyneux P: The use of the stable free radical diphenylpicrylhydrazyl (DPPH) for estimating antioxidant activity. Songklanakarin J Sci Techno 2004, 26:211-219.
30. Foti MC, Daquino C, Mackie ID, DiLabio GA, Ingold KU: Reaction of phenols with the 2,2-diphenyl-1-picrylhydrazyl radical. Kinetics and DFT calculations applied to determine ArO-H bond dissociation enthalpies and reaction mechanism. J Org Chem 2008, 73:9270-9282.

31. Foti MC: Antioxidant properties of phenols. J Pharm Pharmacol 2007, 59:1673-1685.

32. Lucarini M, Pedulli GF: Free radical intermediates in the inhibition of the autoxidation reaction. Chem Soc Rev 2010, 39:2106-2119.

33. Foti MC, Johnson ER, Vinqvist MR, Wright JS, Barclay LRC, Ingold KU: Naphthalene diols: a new class of antioxidants intramolecular hydrogen bonding in catechols, naphthalene diols, and their aryloxyl radicals. J Org Chem 2002, 67:5190-5196.

34. Foti MC, Barclay LRC, Ingold KU: The role of hydrogen bonding on the $\mathrm{H}$-atom-donating abilities of catechols and naphthalene diols and on a previously overlooked aspect of their infrared spectra. J Am Chem Soc 2002, 124:12881-12888.

35. Amorati $R$, Valgimigli $L$ : Modulation of the antioxidant activity of phenols by non-covalent interactions. Org Biomol Chem 2012, 10:4147-4158.

36. Amorati R, Pedulli GF, Valgimigli L: Kinetic and thermodynamic aspects of the chain-breaking antioxidant activity of ascorbic acid derivatives in non-aqueous media. Org Biomol Chem 2011, 9:3792-3800.

37. Brunhuber NMW, Mort JL, Christoffersen RE, Reich NO: Steady-state kinetic mechanism of recombinant avocado ACC oxidase: initial velocity and inhibitor studies. Biochem 2000, 39:10730-10738.

38. Yanishlieva NV, Marinova EM, Gordon MH, Raneva VG: Antioxidant activity and mechanism of action of thymol and carvacrol in two lipid systems. Food Chem 1999, 64:59-66.

39. Bondet V, Brand-Williams W, Berset $C$ : Kinetics and mechanisms of antioxidant activity using the DPPH free radical method. Food Sci Technol 1997, 30:609-615.

40. Foti MC, Daquino C, DiLabio GA, Ingold KU: A meta effect in nonphotochemical processes: the homolytic chemistry of $\mathrm{m}$ methoxyphenol. J Org Chem 2008, 73:2408-2411. b) ibid. J Org Chem 2008, 73:7440-7440

41. Abo Shady A, Ali HM, Sharaf EHA, Abdel-Barry OA: DPPH and hydroxyl radical scavenging and antioxidant activities of anilines and related compounds. Bull Biol Chem Environ Sci 2007, 2:257-266.

42. Cheng Z, Ren J, Li Y, Chang W, Chen Z: Study on the multiple mechanisms underlying the reaction between hydroxyl radical and phenolic compounds by quantitative structure and activity relationship. Bioorg Med Chem 2002, 10:4067-4073.

43. Korycka-Dahi MB, Richardson T: Activated oxygen species and oxidation of food constituents. Crit Rev Food Sci Nutr 1978, 10:209-241.

doi:10.1186/1752-153X-7-53

Cite this article as: Ali et al:: Structural features, kinetics and SAR study of radical scavenging and antioxidant activities of phenolic and anilinic compounds. Chemistry Central Journal 2013 7:53.

Publish with ChemistryCentral and every
scientist can read your work free of charge
"Open access provides opportunities to our
colleagues in other parts of the globe, by allowing
anyone to view the content free of charge."
W. Jeffery Hurst, The Hershey Company.
- available free of charge to the entire scientific community
- peer reviewed and published immediately upon acceptance
- cited in PubMed and archived on PubMed Central
- yours - you keep the copyright
submit your manuscript here:
http://www.chemistrycentral.com/manuscript/

